\title{
Improving diet, physical activity and other lifestyle behaviours using computer-tailored advice in general practice: a randomised controlled trial
}

Sanjoti Parekh ${ }^{1 *}$, Corneel Vandelanotte ${ }^{2}$, David $\mathrm{King}^{3}$ and Frances M Boyle ${ }^{4}$

\begin{abstract}
Background: The adoption and maintenance of healthy behaviours is essential in the primary prevention of chronic non-communicable diseases. This study evaluated the effectiveness of a minimal intervention on multiple lifestyle factors such as diet, physical activity, smoking and alcohol, delivered through general practice, using computer-tailored feedback.

Methods: Adult patients visiting 21 general practitioners in Brisbane, Australia, were surveyed about ten health behaviours that are risk factors for chronic, non-communicable diseases. Those who completed the selfadministered baseline questionnaire entered a randomised controlled trial, with the intervention group receiving computer-tailored printed advice, targeting those health behaviours for which respondents were not meeting current recommendations. The primary outcome was change in summary lifestyle score (Prudence Score) and individual health behaviours at three months. A repeated measures analysis compared change in these outcomes in intervention and control groups after adjusting for age and education.
\end{abstract}

Results: 2306 patients were randomised into the trial. 1711 (76\%) returned the follow-up questionnaire at 3 months. The Prudence Score (10 items) in the intervention group at baseline was 5.88, improving to 6.25 at 3 months (improvement $=0.37$ ), compared with 5.84 to 5.96 (improvement $=0.12$ ) in the control group $(F=13.3$, $p=0.01$ ). The intervention group showed improvement in meeting recommendations for all individual health behaviours compared with the control group. However, these differences were significant only for fish intake (OR 1.37, 95\% Cl 1.11-1.68), salt intake (OR 1.19, 95\% Cl 1.05-1.38), and type of spread used (OR 1.28, 95\% Cl 1.06-1.51).

Conclusion: A minimal intervention using computer-tailored feedback to address multiple lifestyle behaviours can facilitate change and improve unhealthy behaviours. Although individual behaviour changes were modest, when implemented on a large scale through general practice, this intervention appears to be an effective and practical tool for population-wide primary prevention.

Trial Registration: The Australian New Zealand Clinical Trials Registry: ACTRN12611001213932

Keywords: Health promotion, General practitioners, Intervention studies, Primary prevention, Diet, Physical activity, Health behaviours.

\footnotetext{
* Correspondence: s.parekh@uq.edu.au

${ }^{1}$ School of Population Health \& Healthy Communities Research Centre, The

University of Queensland, Herston, Queensland 4006, Australia

Full list of author information is available at the end of the article
}

\section{Biomed Central




\section{Introduction}

Non-communicable diseases (NCDs) are, to varying degrees, associated with a limited set of modifiable health risk behaviours [1-5]. These behaviours are highly prevalent in developed countries; for example, $61 \%$ of the Australian population consumes more alcohol than recommended by current guidelines, $50 \%$ and $86 \%$ respectively fails to eat sufficient fruit and vegetables [6] and 50\% is physically inactive [7] . These risk behaviours are not only highly prevalent but also occur in clusters; for example 99\% of smokers had at least one additional risk such as unhealthy diet, high body mass index (BMI) or insufficient physical activity [8]. Clustering of unhealthy behaviours suggests the need for development and evaluation of interventions that target multiple health behaviours to achieve population health gains [8-10]. There are studies illustrating the limitations of self-regulatory capacity and the operating of concepts such as decision fatigue, indicating that it might be difficult for an individual to make multiple behavioural changes simultaneously [11]. However, multiple-behaviour change interventions are likely to have a greater impact on public health than single-behaviour interventions [4,10,12-14]. Only a limited number of such interventions have been evaluated to date, but generally show promising results $[15,16]$. Furthermore, there is evidence to suggest that interventions targeting more than one behaviour can be effective even when implemented simultaneously across the different behaviours [17-21]. To benefit cost-effectiveness and reduce participant burden, simultaneous interventions are preferred over interventions that target multiple behaviours sequentially [22].

The general or family practice setting offers potential to facilitate multiple behaviour change on a large scale, as approximately $85 \%$ of the Australian population consult a general practitioner (GP) each year [6]. Moreover, a GP's advice is well accepted by patients [23] and reasonably effective in stimulating changes for certain habitual behaviours [24,25]. However, GPs experience crowded agendas and health promotion is often overlooked when patients present for management of acute conditions. A recent Australian study showed that GPs usually assess smoking and alcohol patterns but only about one in four typically assess their patient's dietary and physical activity habits [26]. For interventions to be workable in general practice they must be easily accommodated within established practice routines and shown to have positive patient outcomes. A focus on multiple risk behaviours simultaneously offers a time-efficient approach. Computer-tailored health promotion interventions in this setting have shown promising results [27].

Interventions focused on diet and lifestyle that provide feedback tailored to an individual's needs have demonstrated better feasibility $[28,29]$ and effectiveness [27,30-33] when compared with non-tailored messages. Tailored messages are more likely to be read, remembered, discussed with others and perceived as interesting due to the personal relevance of the advice $[34,35]$. Computer-tailored feedback can be generated by an automated expert system, making it feasible to provide large number of respondents with personally adapted feedback about their present health behaviours [36].

Our previous work indicates that key aspects of diet and lifestyle can be reliably assessed by self-reported surveys [37]. There is growing evidence that multiple health behaviours can be summarised as a composite score and that higher scores are associated with lower morbidity and mortality [38-40]. A summary health score or a lifestyle score can be employed as a simple tool to communicate about the number of behaviours for which recommendations are met hence indicating the scope of change needed. However, little research has been published evaluating the use of such lifestyle score in achieving multiple health behaviour change in the general practice setting. Therefore, the aim of this study was to assess the effectiveness of a minimal intervention based around computer-tailored feedback derived from a summary health behaviour score of ten behaviours, within a representative general practice setting. It is hypothesised that the participants in the intervention group will significantly improve their health behaviours and increase their health score compared to the control group.

\section{Methods}

\section{Study design and participants}

Invitations were sent to 30 GPs in Brisbane, Australia, of whom 21 agreed to participate. The practice manager generated an initial list of patients, aged between 18 and 70 years, who had visited participating GPs in the preceding six months. The GP checked this list and excluded patients with active cancer, receiving renal dialysis, recent cardiovascular event, dementia, any other terminal illness or recent bereavement $(\mathrm{n}=38)$. All communication with the patients originated from the research team, but used the treating doctor's letterhead and electronic signature. Eligible patients received a postal invitation to participate, a study questionnaire and reply-paid envelope. Non-respondents were sent up to two reminder letters and a new copy of the questionnaire at three week intervals. Subjects who failed to respond at this stage were excluded. Return of the questionnaire was regarded as consent to participate in the project. Baseline data were collected for all participants from July to August 2008. The study was approved by the Behavioural and Social Sciences Ethical Review committee of the University of Queensland, Australia.

Patients who responded at baseline were randomised using a permuted block randomisation procedure [41]. 
This 2 X2 factorial design randomised participants into intervention or control group, and for early ( 3 month) or late (12 months) follow-up. Further detail on the overall study design has been published earlier [42]. For each GP the block length was varied between 4, 8 or 12 to accommodate four study groups. Thus they were randomised into four groups as follows: intervention with $3+12$ months follow-up, intervention with 12 months follow-up only, control with $3+12$ months follow-up or control with 12 months follow-up only. Participants who resided at the same address were allocated to the same group as the first respondent from that address. Participants were blind to intervention condition, which was presented as a series of surveys followed by feedback. This paper focuses exclusively on participants reassessed at three months in order to examine the short term impact of the initial intervention. A forthcoming paper will address the sustainability of that change at 12 months and the impact of receiving or not receiving followup at 3 months. Behaviour change outcomes were assessed between Oct-Nov 2008 by re-applying baseline survey measures.

\section{Baseline measures}

The baseline questionnaire used to calculate the Prudence Score has previously been validated [37] and includes 26 questions related to ten health behaviours and nine questions collecting demographic information. Responses to items addressing smoking, physical activity (using short version of International Physical Activity Questionnaire [43]), intake of alcohol, meat, fish, fruit and vegetables, use of unsaturated fats as spreads, avoidance of added salt, type of milk consumed, and body mass index (BMI, based on self-reported height and weight) were dichotomised. Each behavioural item was assigned a score of ' 1 ' if achieving or exceeding recommendations, or a score of ' 0 '. Scores were based on guidelines promulgated by the National Health and Medical Research Council (NHMRC) and the National Heart Foundation of Australia (NHF) (see Table 1). Individual health behaviour scores were summed to yield a combined lifestyle score, the Prudence Score, ranging between 0 and 10. The remaining items in the baseline questionnaire addressed other health behaviours such as tetanus immunization, sun protection behaviour, non-smoking policies in private homes, and participation in mammography and cervical

Table 1 Socio-demographic and health behaviour characteristics at baseline $(n=1683)$, (mean \pm SD for continuous data and percentages for categorical data)

\begin{tabular}{|c|c|c|c|}
\hline Characteristics & Intervention $(n=853)$ & Control $(n=830)$ & Chi2 or F( $p$-value) \\
\hline \multicolumn{4}{|l|}{ Demographics } \\
\hline Mean Age & $49.2 \pm 13.5$ & $48.1 \pm 13.5$ & $3.00\left(0.08^{\mathrm{a}}\right)$ \\
\hline Gender (\% women) & $68.5 \%$ & $70.2 \%$ & $0.62\left(0.42^{b}\right)$ \\
\hline Full or part time employment & $63.5 \%$ & $66.5 \%$ & $1.67\left(0.19^{b}\right)$ \\
\hline Married or living as married & $71 \%$ & $70 \%$ & $3.51\left(0.66^{b}\right)$ \\
\hline Education (\%Tertiary) & $59.2 \%$ & $55.5 \%$ & $2.35\left(0.12^{b}\right)$ \\
\hline \multicolumn{4}{|l|}{ Health Behaviours } \\
\hline Meat intake $\leq 4$ serves per week & $70.2 \%$ & $68.7 \%$ & $0.44\left(0.50^{b}\right)$ \\
\hline Fish intake $\geq 2$ serves per week & $68.1 \%$ & $71.2 \%$ & $0.36\left(0.17^{b}\right)$ \\
\hline Use of low or no fat milk & $70.6 \%$ & $71.4 \%$ & $1.90\left(0.69^{b}\right)$ \\
\hline Salt: No added salt & $46.2 \%$ & $44.7 \%$ & $0.36\left(0.54^{b}\right)$ \\
\hline Vegetables and fruit: 7 serves per day & $14.2 \%$ & $12.4 \%$ & $1.10\left(0.29^{b}\right)$ \\
\hline Use of spreads other than butter & $69.1 \%$ & $67.4 \%$ & $0.56\left(0.45^{b}\right)$ \\
\hline Physical activity $\geq 150$ minutes per week & $48.4 \%$ & $48.7 \%$ & $0.01\left(0.89^{b}\right)$ \\
\hline Alcohol $\leq 2$ standard drinks per day & $70.9 \%$ & $71.4 \%$ & $0.05\left(0.80^{b}\right)$ \\
\hline No Smoking & $87.0 \%$ & $88.4 \%$ & $0.75\left(0.38^{b}\right)$ \\
\hline Body weight between 18.5 to $24.99 \mathrm{~kg} / \mathrm{m} 2$ & $26.4 \pm 5.6$ & $26.5 \pm 5.6$ & $0.35\left(0.56^{\mathrm{a}}\right)$ \\
\hline \multicolumn{4}{|l|}{ Mean Prudence Score } \\
\hline Total $(n=1599)$ & $5.88 \pm 1.6$ & $5.84 \pm 1.7$ & $0.19\left(0.66^{\mathrm{a}}\right)$ \\
\hline Men $(n=495)$ & $5.60 \pm 1.6$ & $5.44 \pm 1.7$ & $1.00\left(0.31^{\mathrm{a}}\right)$ \\
\hline Women $(n=1104)$ & $6.01 \pm 1.6$ & $6.02 \pm 1.6$ & $0.01\left(0.96^{\mathrm{a}}\right)$ \\
\hline
\end{tabular}

a ANOVA tested continuous variables.

b Chi-squared tested categorical variables. 
cytology screening. These items did not contribute to the Prudence Score.

\section{Intervention}

All participants in the intervention group received only information related to the ten health behaviours comprising the Prudence Score. The intervention material consisted of:

(a) Personalised computer-tailored feedback: A one page personalised, computer-tailored feedback letter, printed on the treating practitioner's letterhead, summarised the participant's health score and indicated behaviours for which they were and were not meeting guideline recommendations.. This letter encouraged the adoption of at least one behaviour not currently contributing to the individual's Prudence Score. The decision as to which additional behaviour(s) to improve was the patient's own.

(b) Health Promotion Information Material: One page health promotion material was distributed to participants only for behaviours for which they were not meeting national guidelines, as indicated by their individual Prudence Score. For example, participants who did not meet NHMRC guidelines for vegetable intake but did meet recommendations for fruit intake only received the information sheet related to daily vegetable intake. The contents of the one page information sheet included the current guidelines for each particular health behaviour, some tips that may make it easier to adhere to this guideline, information related to the health benefits when adhering to the guideline and links where participants could find more information about this health behaviour from credible sources (e.g. the National Heart Foundation of Australia, the World Health Organisation, the Cancer Council Australia).

A publication by Kinzie draws on the recommendations of health behavioural theorists, and provides a unified framework from which to apply these theories in the design of health education. The authors offer a unified set of instructional design strategies for health education interventions by using a modified Events of Instruction framework (adapted from Robert Gagne) [44]. The framework includes five important strategies: gain attention, present stimulus material, provide guidance, elicit performance and provide feedback. Further, the intervention also applied the 'Elaboration Likelihood Model' by Petty and Cacioppo (1986) [45], which postulates that people will provide more attention to health information when it is perceived as personally relevant.

Similar to the intervention group, the control group received an individualised letter and tailored information sheets about the five health protective behaviours not included in the Prudence Score (sun protection, updating tetanus vaccination, mammogram and Pap smear). Feedback to the control group on these other behaviours was provided in an attempt to reduce attrition and to ensure both groups were treated comparably for a better test of the intervention. Participants in both groups received their personalised feedback within 10 days of the project team receiving their completed baseline survey. The processing of this information (data entry, generating the print-based personalised feedback using the custom software available to the project team and placing it in a new envelope) took on average 5 minutes per participant.

\section{Statistical analysis}

Power calculations for the main study were based on pilot study results [37] (mean Prudence Score 4.94, SD 1.7). To have a $95 \%$ chance of the proportion with a Prudence score of 6 or more increase from $39 \%$ to $45 \%$, using two-sided $\alpha=0.05$, required a total of 6600 invitations to participate, accounting for $20 \%$ loss to follow up and response fraction of $60 \%$ achieved in the pilot study.

Baseline differences in groups were analysed using one-way ANOVA for testing continuous variables and Chi-squared test for categorical variables. The primary outcome was change in mean Prudence Score at three months; this was assessed using T-tests and repeated measure ANOVAs. This analysis was adjusted for gender and age. The secondary outcome was measuring change in the proportion of participants adhering to individual behavioural items. This was measured using General Estimating Equations Models, in order to obtain odds ratios that examined associations between changes in individual health behaviours in the intervention group over and above the control group. Number-needed-to-treat (NNT) is the number of participants that needed to receive an intervention to achieve change in one individual. NNT was calculated using difference between change in control events and change in the experimental group. Inverse of that difference provided the number needed to treat. Initial analysis excluded participants with missing data at 3 month follow-up. However, this per protocol assessment was complemented by an intention-to-treat analysis, in which we assumed that patients lost to follow-up had not changed their behaviour. Significance was set at $P<0.05$ for all analyses.

\section{Results}

Invitations and questionnaires were mailed to 8243 patients, after 38 were excluded by their treating GP. 4678 patients agreed to participate in the study by returning completed questionnaires, giving a baseline response of $56.5 \%$, see Figure 1. Health behaviour changes reported are only for participants in the sub-study to be reassessed 


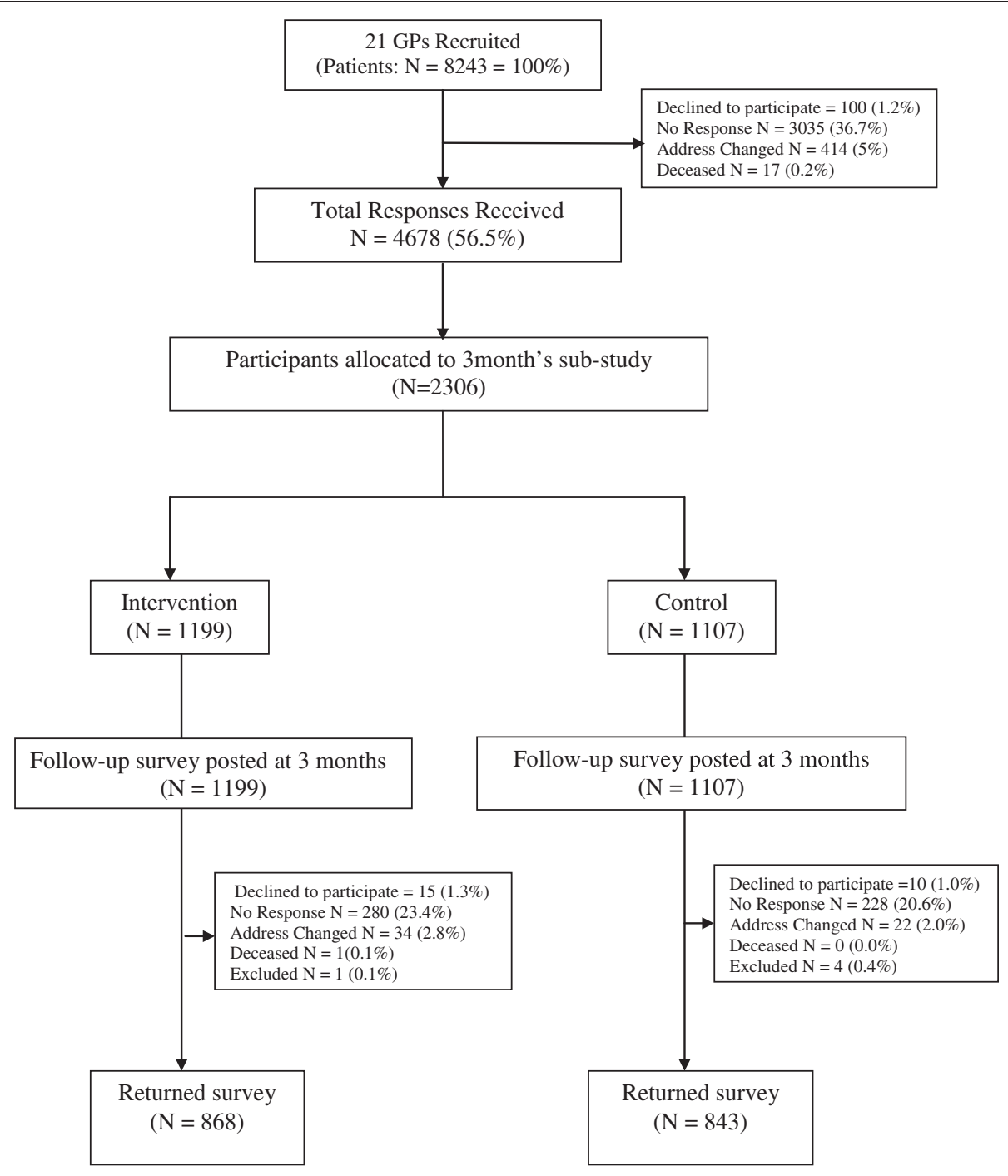

Figure 1 Flowchart of participant recruitment and randomisation.

at 3 months $(n=2306)$. A total of $76 \%(n=1711)$ participants responded at three months. Twenty nine participants had excessive missing data and were excluded; hence the final sample consisted of 1683 participants. Participants had a mean age of 48.6 years $(\mathrm{SD}=13.5)$, mean $\mathrm{BMI}$ in the overweight range $(26.4 \mathrm{~kg} / \mathrm{m} 2$; $\mathrm{SD}=5.4)$ and were predominantly female (69.7\%). There were no significant differences between groups at baseline in gender, health behaviours (See Table 1), or mean Prudence score (5.88 versus $5.84, P=0.65)$.

\section{Individual health behaviours}

There was an overall improvement in health behaviours in both intervention and control groups at three months (Table 2). More improvement was noted in the intervention group compared to the control group, except for smoking prevalence (Table 2). However, significant changes between groups were observed for only three behaviours: increased fish intake (OR 1.37, CI 1.11-1.64), reduced salt intake (OR 1.19, CI 1.05-1.38) and using spreads other than butter (OR 1.28 CI 1.06-1.51). The odds ratios for change in intervention group compared to the control group, adjusted for age and gender, are included in Table 2. Participants in the intervention group were $40 \%$ more likely to increase their fish intake as compared to controls. Similarly, the intervention group were $20 \%$ and $30 \%$ respectively more likely to reduce salt intake and use of spreads other than butter. The number needed to treat (NNT) indicates, taking fish intake as an example, that for every 15 patients receiving the intervention one individual will adopt sufficient change to achieve guideline recommended fish intake. Apart from the minimal change seen in body weight and smoking, all other behaviours recorded NNT of between 15 and 58 (Table 2). 
Table 2 Net percentage change, odds of change and number needed to treat (NNT) for participants achieving guidelines recommendations $(n=1683)$

\begin{tabular}{|c|c|c|c|c|c|}
\hline Health Behaviour & Group & Net change $\%$ & Odds Ratio for change & $95 \% \mathrm{Cl}$ & NNT\# \\
\hline \multirow[t]{2}{*}{ Fish } & Intervention & +7.06 & $1.37^{*}$ & $1.11-1.64$ & 15 \\
\hline & Control & +0.84 & & & \\
\hline \multirow[t]{2}{*}{ Spread } & Intervention & +5.06 & $1.28^{*}$ & $1.06-1.51$ & 21 \\
\hline & Control & +0.37 & & & \\
\hline \multirow[t]{2}{*}{ Salt } & Intervention & +5.43 & $1.19^{*}$ & $1.05-1.38$ & 24 \\
\hline & Control & +1.23 & & & \\
\hline \multirow[t]{2}{*}{ Veg and fruit } & Intervention & +3.14 & 1.24 & $0.91-1.68$ & 37 \\
\hline & Control & +0.49 & & & \\
\hline \multirow[t]{2}{*}{ Meat } & Intervention & +7.17 & 1.16 & $0.93-1.44$ & 38 \\
\hline & Control & +4.48 & & & \\
\hline \multirow[t]{2}{*}{ Milk } & Intervention & +4.62 & 1.11 & $0.96-1.29$ & 45 \\
\hline & Control & +1.80 & & & \\
\hline \multirow[t]{2}{*}{ Alcohol } & Intervention & +3.88 & 1.16 & $0.96-1.37$ & 45 \\
\hline & Control & +1.12 & & & \\
\hline \multirow[t]{2}{*}{ Physical activity } & Intervention & +0.48 & 1.06 & $0.86-1.30$ & 58 \\
\hline & Control & -1.34 & & & \\
\hline \multirow[t]{2}{*}{ Body weight } & Intervention & -0.12 & 0.96 & 0.85-1.09 & 161 \\
\hline & Control & -0.82 & & & \\
\hline \multirow[t]{2}{*}{ Smoking } & Intervention & +0.24 & 0.97 & $0.86-1.12$ & 1000 \\
\hline & Control & +0.36 & & & \\
\hline
\end{tabular}

*Significant Results $(p<0.05)$.

\#NNT : Number needed to treat.

\section{Prudence score}

The change in the Prudence Score from baseline to three months was significantly greater in the intervention group (5.88 to 6.25 , difference +0.37 ) when compared to the control group (5.84 to 5.96 , diff $=0.12$ ) $(\mathrm{F}=13.3, \mathrm{p}=0.01)$. (Table 3$)$ Similar changes at 3 months were observed for men $(\mathrm{F}=4.6, P=0.03)$ and women $(\mathrm{F}=8.6, P=0.003)$. The participants who were lost to follow-up at three months had significantly lower Prudence Score at baseline compared to continuing participants (5.35 versus $5.85, \mathrm{~F}=2.8, \mathrm{p}=0.02)$. However, with an intention-to-treat analysis the mean Prudence Score still showed significant increase in the intervention group compared to the control group (6.02 versus 5.74, $\mathrm{F}=11.58, \mathrm{P}<0.001)$.

When participants were categorised into 3 groups according to the baseline Prudence Scores (Table 4), the maximum improvement in Prudence Score was observed in the low baseline score group, an increase of 1.18 in the intervention group, but low scoring controls also improved their Prudence score by 0.82 (net difference +0.36 ). Both groups of participants with high baseline scores reported a decline in Prudence scores at 3 months, but a significantly lesser reduction in the intervention group (net difference of +0.61 ) suggested that the intervention was possibly most effective in participants already following predominantly healthy behaviours.

\section{Discussion}

The primary aim of this study was to assess the effectiveness of a minimal, computer-tailored intervention in a primary care setting using a summary health behaviour score. This intervention was effective in increasing the lifestyle score over a three month period, although a statistically significant positive change was observed in only three individual health behaviours. The implications of this study are supported by primary prevention studies that have demonstrated morbidity and mortality benefits from lifestyle behaviour change $[40,46,47]$.

Study participants showed a significant increased adherence to guidelines for salt intake, fish intake and type of spread used. A similar increase in fish consumption was observed in an intervention study by Sacerdote et al. [48]. Other interventions targeting self-reported dietary intake in primary care populations have produced only small improvements, consistent with our results on fruit and vegetable intake [49]. The three behaviours that showed significant improvements are probably easier to adopt due to simple substitution, for example using margarine rather than butter. Behaviours such as increasing 
Table 3 Effect of intervention on the Prudence Score at 3 months $(n=1599)$

\begin{tabular}{|c|c|c|c|c|c|}
\hline & $\frac{\text { Intervention }}{\text { Prudence Score }(95 \% \mathrm{Cl})}$ & $\frac{\text { Control }}{\text { Prudence Score }(95 \% \mathrm{Cl})}$ & $T$-test ( $p$ value) ${ }^{a}$ & $\begin{array}{l}\text { Repeated } \\
\text { Measures } \\
\text { ANOVA }^{\mathrm{b}}\end{array}$ & $\begin{array}{l}\text { Repeated } \\
\text { Measures } \\
\text { ANOVA }^{c}\end{array}$ \\
\hline \multicolumn{6}{|l|}{ Total } \\
\hline Baseline & $5.88(5.77-5.99)$ & $5.84(5.73-5.96)$ & $t=0.44(p=0.66)$ & $F=13.3 P=0.01$ & $F=11.58 p<0.001$ \\
\hline 3 months & $6.25(6.13-6.36)$ & $5.96(5.84-6.08)$ & $t=3.47(p=0.001)$ & & \\
\hline Net Change & 0.37 & 0.12 & & & \\
\hline \multicolumn{6}{|l|}{ Men } \\
\hline Baseline & $5.60(5.39-5.80)$ & $5.45(5.22-5.67)$ & $t=0.99(p=0.32)$ & $F=4.6 p=0.03$ & $F=4.0 P=0.04$ \\
\hline 3 months & $5.92(5.72-6.13)$ & $5.55(5.33-5.77)$ & $t=2.45(p=0.014)$ & & \\
\hline Net Change & 0.32 & 0.10 & & & \\
\hline \multicolumn{6}{|l|}{ Women } \\
\hline Baseline & $6.01(5.88-6.14)$ & $6.01(5.88-6.16)$ & $t=0.04(p=0.96)$ & $F=8.6 p=0.003$ & $F=7.6 P=0.006$ \\
\hline 3 months & $6.40(6.26-6.54)$ & $6.13(5.99-6.27)$ & $t=2.72(p=0.006)$ & & \\
\hline Net Change & 0.39 & 0.12 & & & \\
\hline
\end{tabular}

a $T$-test is used to assess the difference between intervention and control group at baseline or 3 months in the P-Score.

b ANOVA adjusted for gender and age.

c ANOVA adjusted for gender and age with intention-to-treat analysis.

physical activity or smoking cessation probably require greater organisation and motivation. It is likely that the minimal intervention provided was insufficient to enhance organisational skills or able to reinforce motivation to change these complex behaviours. None the less, success in adopting easy behaviours might increase confidence and self-efficacy to facilitate subsequent attempts at more difficult to change behaviours [50].

The response fractions at baseline (57\%) and three months (76\%) are comparable to other studies undertaken in general practice settings [51]. The strategies used in this trial, such as repeat mailing to initial non-responders, GP endorsement and shorter questionnaires, have been shown to improve response to postal questionnaires in health care research [52]. GP endorsement of invitation letters and questionnaires may have improved the extent of behaviour change detected, due to the authority and esteem held by patients for their doctor.

Women in the study had significantly higher Prudence Scores than men at baseline and at three months. The change over time was also greater in women; though not significantly so. Similar gender differences in health have been observed in other studies [53,54]. This difference could be partly due to women accompanying their children for medical attention and their more regular attendance for contraception and screening tests. Women make up $60 \%$ of visits to Australian general practices [55] and are therefore more likely to receive greater exposure to health information. However, our finding that this intervention was equally effective in changing behaviours in both men and women might provide opportunities to close the gender gap. As men are traditionally harder to reach with health messages than women [56],

Table 4 Effect of intervention on the P-Score $(n=1599)$ for high, medium and low scores at baseline

\begin{tabular}{|c|c|c|c|c|}
\hline Prudence Score Category\# & Mean score at baseline (SE) & Mean score at 3 months (SE) & Net difference & Repeated measures ANOVA* \\
\hline \multicolumn{5}{|l|}{ Low Scorer (0-4) } \\
\hline Intervention & $3.40(0.047)$ & $4.58(0.113)$ & 1.18 & $F=4.18 p=0.04$ \\
\hline Control & $3.44(0.053)$ & $4.26(0.109)$ & 0.82 & \\
\hline \multicolumn{5}{|l|}{ Medium Scorer (5-7) } \\
\hline Intervention & $6.00(0.030)$ & $6.32(0.059)$ & 0.32 & $F=6.82 p=0.01$ \\
\hline Control & $5.92(0.031)$ & $6.04(0.058)$ & 0.12 & \\
\hline \multicolumn{5}{|l|}{ High Scorer (8-10) } \\
\hline Intervention & $8.33(0.048)$ & $8.04(0.101)$ & -0.29 & $F=4.97 p=0.03$ \\
\hline Control & $8.33(0.044)$ & $7.33(0.109)$ & -1.0 & \\
\hline
\end{tabular}

*ANOVA adjusted for gender and age.

\# Participants grouped into 3 score categories based on their baseline health scores. 
the minimalist nature of our intervention might be better suited for them.

Limitations of our study include firstly the dichotomous scoring system for health behaviours, where subthreshold change in behaviour remains undetected. Yet this would suggest that our results might have underestimated the real extent of behaviour change. However, the Prudence Score is designed for simplicity in order to provide easy to interpret feedback about health behaviours to large numbers of patients. Secondly, the ten component behaviours are equally weighted in their contribution to the Prudence Score, rather than being weighted according to their relative impacts on health. Dietary factors are over represented compared to exercise and smoking, which only contributed a single score each. A study employing an equally weighted lifestyle scoring system used all the same items as the Prudence Score ( except vegetable and fruit intake and type of spread ) to predict mortality in both healthy elderly men and older men with established vascular disease $[39,57]$. It was able to demonstrate a linear relationship between increasing lifestyle score and decreasing mortality rate with an absolute reduction in cumulative mortality of $0.62 \%$ per single additional healthy behaviour [57] . This suggests that the aggregate score is a meaningful summary of an individual's effort to protect their health. However, assessing the direct impact of the Prudence score on morbidity and mortality is beyond the scope of this trial. Thirdly, the use of self-reported data was a potential weakness: however the assessment questionnaire was previously validated [37] and our study participants were representative of the wider Australian population $[6,58]$. Finally, as this project provided printbased feedback to participants the process of data collection and feedback provision was labour intensive. However, a fully automated implementation, applying waiting-room kiosks or tablets, can easily be developed based on this study. Further research is needed to determine the effectiveness of a fully automated version of this intervention.

Our study had several strengths: a randomised design with allocation concealment, measurement of individual as well as aggregate changes in health behaviours and a large sample size. Lifestyle interventions focused on prevention must be effective but also available and accessible to the public. The ten behaviours in the Prudence Score can be measured by an individual without the help of a health professional. Lifestyle changes arising from this intervention were achieved without face-toface intervention or planned GP advice and are likely to be cost effective outside the research setting. A particular advantage of this intervention is its population coverage given very high levels of access to primary care in Australia [6].

\section{Conclusion}

Finding feasible and innovative ways to use technology for improving health behaviours in large numbers of individuals is vital for the primary prevention of NCDs. Geoffrey Rose's notion that population-wide strategies are likely to be more effective than those that focus on high-risk individuals [59] calls for research into such minimal, wide-reach interventions. This study contributes to this research agenda by extending the limited evidence currently available in the field of multiple health behaviour change intervention trials in the general practice setting. Although the individual behaviour changes resulting from this intervention were relatively modest, the Prudence Score, which can be implemented on a large scale and is easy to calculate, appears to be a useful tool for improving behaviours in primary prevention.

\section{Abbreviations}

BMI: Body mass index; GP: General practitioner; NCD: Non-communicable disease; NHF: National heart foundation; NHMRC: National health and medical research council; NNT: Number needed to treat.

\section{Competing interests}

The author(s) declare that they have no competing interests.

\section{Authors contributions}

SP recruited the general practitioners and study participants, collected and analysed the data and drafted the manuscript. DK participated in recruiting general practitioners. CV also provided supervision in generating tailored feedback and health promotion materials. DK, FB and CV helped to draft the manuscript. SP, CV, DK, and FB read and approved the final manuscript.

\section{Acknowledgements}

We acknowledge the late Professor Konrad Jamrozik's contribution to the conception, design and implementation of the study prior to his death in March 2010. This work was funded by the MBF Foundation (currently BUPA Health Foundation), a charitable organisation. SP was supported by a

National Health and Medical Research Council of Australia post-graduate scholarship (2007-09). CV is supported by a National Health and Medical Research Council of Australia (\#519778) and National Heart Foundation of Australia (\#PH 07B 3303) post-doctoral research fellowship. We sincerely thank the patients, doctors and staff of the general practices involved with this project.

\section{Author details}

${ }^{1}$ School of Population Health \& Healthy Communities Research Centre, The University of Queensland, Herston, Queensland 4006, Australia. ${ }^{2}$ Institute for Health and Social Science Research, Central Queensland University, Rockhampton, Queensland, Australia. ${ }^{3}$ School of Medicine, The University of Queensland, Herston, Queensland 4006, Australia. ${ }^{4}$ The University of Queensland, School of Population Health, Qld 4006, Australia.

Received: 9 December 2011 Accepted: 30 August 2012

Published: 11 September 2012

\section{References}

1. Australian Institute of Health and Welfare: Chronic Disease and Associated Risk Factors. Canberra: AlHW2002; 2001.

2. Kromhout D, Menotti A, Kesteloot H, Sans S: Prevention of coronary heart disease by diet and lifestyle: evidence from prospective cross-cultural, cohort, and intervention studies. Circulation 2002, 105(7):893-898.

3. Dickinson HO, Mason JM, Nicolson DJ, Campbell F, Beyer FR, Cook JV, Williams B, Ford GA: Lifestyle interventions to reduce raised blood pressure: a systematic review of randomized controlled trials. $J$ Hypertens 2006, 24(2):215-233. 
4. Prochaska JO, Velicer WF, Redding C, Rossi JS, Goldstein M, DePue J, Greene GW, Rossi SR, Sun X, Fava JL, Laforge R, Rakowski W, Plummer BA: Stagebased expert systems to guide a population of primary care patients to quit smoking, eat healthier, prevent skin cancer, and receive regular mammograms. Prev Med 2005, 41(2):406-416.

5. Key TJ, Allen NE, Spencer EA, Travis RC: The effect of diet on risk of cancer Lancet 2002, 360(9336):861-868.

6. Australian Institute of Health and Welfare: Australia's Health. Canberra: AlHW 2008; 2008

7. Australian Institute of Health and Welfare: Chronic diseases and associated risk factors. Canberra: AlHW 2006; 2005.

8. Pronk NP, Anderson LH, Crain AL, Martinson BC, O'Connor PJ, Sherwood NE, Whitebird RR: Meeting recommendations for multiple healthy lifestyle factors. Prevalence, clustering, and predictors among adolescent, adult, and senior health plan members. Am J Prev Med 2004, 27(2 Suppl):25-33.

9. Ma J, Betts NM, Hampl JS: Clustering of lifestyle behaviors: the relationship between cigarette smoking, alcohol consumption, and dietary intake. Am J Health Promot 2000, 15(2):107-117.

10. Prochaska JJ, Sallis JF: A randomized controlled trial of single versus multiple health behavior change: promoting physical activity and nutrition among adolescents. Health Psychol 2004, 23(3):314-318.

11. Vohs KD, Baumeister RF, Schmeichel BJ, Twenge JM, Nelson NM, Tice DM: Making choices impairs subsequent self-control: a limited-resource account of decision making, self-regulation, and active initiative. $J$ Pers Soc Psychol 2008, 94(5):883-898.

12. Daubenmier JJ, Weidner G, Sumner MD, Mendell N, Merritt-Worden T, Studley J, Ornish D: The contribution of changes in diet, exercise, and stress management to changes in coronary risk in women and men in the multisite cardiac lifestyle intervention program. Ann Behav Med 2007, 33(1):57-68.

13. De Vries H, Kremers SP, Smeets T, Brug J, Eijmael K: The effectiveness of tailored feedback and action plans in an intervention addressing multiple health behaviors. Am J Health Promot 2008, 22(6):417-425

14. Yancey AK, McCarthy WJ, Harrison GG, Wong WK, Siegel JM, Leslie J: Challenges in improving fitness: results of a community-based, randomized, controlled lifestyle change intervention. J Womens Health (Larchmt) 2006, 15(4):412-429.

15. Sciamanna CN, Marcus BH, Goldstein MG, Lawrence K, Swartz S, Bock B, Graham AL, Ahern DK: Feasibility of incorporating computer-tailored health behaviour communications in primary care settings. Inform Prim Care 2004, 12(1):40-48

16. Prochaska JO, Velicer WF, Rossi JS, Redding CA, Greene GW, Rossi SR, Sun X, Fava JL, Laforge R, Plummer BA: Multiple risk expert systems interventions: impact of simultaneous stage-matched expert system interventions for smoking, high-fat diet, and sun exposure in a population of parents. Health Psychol 2004, 23(5):503-516.

17. Glasgow RE, Goldstein MG, Ockene JK, Pronk NP: Translating what we have learned into practice. Principles and hypotheses for interventions addressing multiple behaviors in primary care. Am J Prev Med 2004 27(2 Suppl):88-101.

18. Goldstein MG, Whitlock EP, DePue J: Multiple behavioral risk factor interventions in primary care. Summary of research evidence. Am J Prev Med 2004, 27(2 Suppl):61-79.

19. Fine LJ, Philogene GS, Gramling R, Coups EJ, Sinha S: Prevalence of multiple chronic disease risk factors. 2001 national health interview survey. Am J Prev Med 2004, 27(2 Suppl):18-24.

20. Coups EJ, Gaba A, Orleans CT: Physician screening for multiple behavioral health risk factors. Am J Prev Med 2004, 27(2 Suppl):34-41.

21. Pronk NP, Peek CJ, Goldstein MG: Addressing multiple behavioral risk factors in primary care. A synthesis of current knowledge and stakeholder dialogue sessions. Am J Prev Med 2004, 27(2 Suppl):4-17.

22. Vandelanotte C, Reeves MM, Brug J, De Bourdeaudhuij I: A randomized trial of sequential and simultaneous multiple behavior change interventions for physical activity and fat intake. Prev Med 2008, 46(3):232-237.

23. Glasgow RE, Bull SS, Gillette C, Klesges LM, Dzewaltowski DA: Behavior change intervention research in healthcare settings: a review of recent reports with emphasis on external validity. Am J Prev Med 2002, 23(1):62-69.

24. Kreuter MW, Chheda SG, Bull FC: How does physician advice influence patient behavior? Evidence for a priming effect. Arch Fam Med 2000, 9 (5):426-433.
25. Reiff-Hekking S, Ockene JK, Hurley TG, Reed GW: Brief physician and nurse practitioner-delivered counseling for high-risk drinking. Results at 12-month follow-up. J Gen Intern Med 2005, 20(1):7-13.

26. Denney-Wilson E, Fanaian M, Wan Q, Vagholkar S, Schutze H, Mark M: Lifestyle risk factors in general practice - routine assessment and management. Aust Fam Physician 2010, 39(12):950-953.

27. Carlfjord S, Nilsen P, Leijon M, Andersson A, Johansson K, Bendtsen P: Computerized lifestyle intervention in routine primary health care: evaluation of usage on provider and responder levels. Patient Educ Couns 2009, 75(2):238-243.

28. Vandelanotte C, De Bourdeaudhuij I: Acceptability and feasibility of a computer-tailored physical activity intervention using stages of change: project FAITH. Health Educ Res 2003, 18(3):304-317.

29. Haerens L, Deforche B, Vandelanotte C, Maes L, De Bourdeaudhuij I: Acceptability, feasibility and effectiveness of a computer-tailored physical activity intervention in adolescents. Patient Educ Couns 2007, 66 (3):303-310.

30. Bull FC, Kreuter MW, Scharff DP: Effects of tailored, personalized and general health messages on physical activity. Patient Educ Couns 1999, 36 (2):181-192.

31. Dutton GR, Provost BC, Tan F, Smith D: A tailored print-based physical activity intervention for patients with type 2 diabetes. Prev Med 2008, 47 (4):409-11.

32. Neville LM, O'Hara B, Milat A: Computer-tailored physical activity behavior change interventions targeting adults: a systematic review. Int J Behav Nutr Phys Act 2009, 6:30.

33. Strecher V, Wang C, Derry H, Wildenhaus K, Johnson C: Tailored interventions for multiple risk behaviors. Health Educ Res 2002, 17(5):619-626.

34. Brug J, Steenhuis I, Van Assema P, De Vries H: The impact of a computertailored nutrition intervention. Prev Med 1996, 25(3):236-242.

35. Skinner CS, Campbell MK, Rimer BK, Curry S, Prochaska JO: How effective is tailored print communication? Ann Behav Med 1999, 21 (4):290-298.

36. de Vries H, Brug J: Computer-tailored interventions motivating people to adopt health promoting behaviours: introduction to a new approach. Patient Educ Couns 1999, 36(2):99-105.

37. Parekh S, King D, Owen N, Jamrozik K: Spousal concordance and reliability of the 'Prudence Score' as a summary of diet and lifestyle. Aust N Z J Public Health 2009, 33(4):320-324.

38. Jiao L, Mitrou PN, Reedy J, Graubard BI, Hollenbeck AR, Schatzkin A, Stolzenberg-Solomon R: A combined healthy lifestyle score and risk of pancreatic cancer in a large cohort study. Arch Intern Med 2009, 169 (8):764-770.

39. Spencer CA, Jamrozik K, Norman PE, Lawrence-Brown M: A simple lifestyle score predicts survival in healthy elderly men. Prev Med 2005, 40(6):712-717.

40. Tamakoshi A, Tamakoshi K, Lin Y, Yagyu K, Kikuchi S: Healthy lifestyle and preventable death: findings from the Japan Collaborative Cohort (JACC) Study. Prev Med 2009, 48(5):486-492.

41. Beller EM, Gebski V, Keech AC: Randomisation in clinical trials. Med J Aust 2002, 177(10):565-567.

42. Parekh S, Vandelanotte C, King D, Boyle FM: Design and baseline characteristics of the 10 Small Steps Study: a randomised controlled trial of an intervention to promote healthy behaviour using a lifestyle score and personalised feedback. BMC Public Health 2012, 12:179.

43. Craig CL MA, Sjostrom M, Bauman AE, Booth ML, Ainsworth BE, Pratt M, Ekelund U, Yngve A, Sallis JF, Oja P: International physical activity questionnaire: 12-country reliability and validity. Med Sci Sports Exerc 2003, 35(8):1381-1395.

44. Kinzie MB: Instructional design strategies for health behavior change. Patient Educ Couns 2005, 56(1):3-15.

45. Petty RE, Cacioppo JT: The Elaboration Likelihood Model of persuasion. In Advances in experimental social psychology, Volume 19. Edited by Berkowitz L. New York: Academic; 1986:123-205.

46. Brunner EJ, Mosdol A, Witte DR, Martikainen P, Stafford M, Shipley MJ, Marmot MG: Dietary patterns and 15-y risks of major coronary events, diabetes, and mortality. Am J Clin Nutr 2008, 87(5):1414-1421.

47. Chiuve SE, Rexrode KM, Spiegelman D, Logroscino G, Manson JE, Rimm EB: Primary prevention of stroke by healthy lifestyle. Circulation 2008, 118 (9):947-954 
48. Sacerdote C, Fiorini L, Rosato R, Audenino M, Valpreda M, Vineis $P$ : Randomized controlled trial: effect of nutritional counselling in general practice. Int J Epidemiol 2006, 35(2):409-415.

49. Ammerman AS, Lindquist CH, Lohr KN, Hersey J: The efficacy of behavioral interventions to modify dietary fat and fruit and vegetable intake: a review of the evidence. Prev Med 2002, 35(1):25-41.

50. Strecher VJ, DeVellis BM, Becker MH, Rosenstock IM: The role of self-efficacy in achieving health behavior change. Health Educ Q 1986, 13(1):73-92.

51. van Sluijs EM, van Poppel MN, Twisk JW, Chin APMJ, Calfas KJ, van Mechelen W: Effect of a tailored physical activity intervention delivered in general practice settings: results of a randomized controlled trial. Am J Public Health 2005, 95(10):1825-1831.

52. Nakash RA, Hutton JL, Jorstad-Stein EC, Gates S, Lamb SE: Maximising response to postal questionnaires-a systematic review of randomised trials in health research. BMC Med Res Methodol 2006, 6:5.

53. Liang W, Shediac-Rizkallah MC, Celentano DD, Rohde C: A populationbased study of age and gender differences in patterns of health-related behaviors. Am J Prev Med 1999, 17(1):8-17.

54. Hjartaker A, Lund E: Relationship between dietary habits, age, lifestyle, and socio-economic status among adult Norwegian women. The Norwegian Women and Cancer Study. Eur J Clin Nutr 1998, 52(8):565-572.

55. Bayram C, Britt H, Kelly Z, Valenti L: Male consultations in general practice in Australia 1999-00. Cat No GEP 11 2003: 15.

56. Courtenay WH: Constructions of masculinity and their influence on men's well-being: a theory of gender and health. Soc Sci Med 2000, 50(10):1385-1401.

57. Spencer CA, Jamrozik K, Lawrence-Brown M, Norman PE: Lifestyle still predicts mortality in older men with established vascular disease. Prev Med 2005, 41(2):583-588.

58. Britt H, Miller GC, Charles J, Bayram C, et al: General practice activity in Australia 2006-07. 2008 Report No.: General Practice Series no 21 Cat. no. GEP 21 Canberra:AlHW.

59. Rose G: Sick individuals and sick populations. Int J Epidemiol 1985, 14 (1):32-38.

doi:10.1186/1479-5868-9-108

Cite this article as: Parekh et al:: Improving diet, physical activity and other lifestyle behaviours using computer-tailored advice in general practice: a randomised controlled trial. International Journal of Behavioral Nutrition and Physical Activity 2012 9:108.

\section{Submit your next manuscript to BioMed Central and take full advantage of:}

- Convenient online submission

- Thorough peer review

- No space constraints or color figure charges

- Immediate publication on acceptance

- Inclusion in PubMed, CAS, Scopus and Google Scholar

- Research which is freely available for redistribution

Submit your manuscript at www.biomedcentral.com/submit
Ciomed Central 